\title{
APLICAÇÃO DE GEOFÍSICA NA OBTENÇÃO DE INFORMAÇÕES PARA MAPEAMENTO GEOTÉCNICO
}

\author{
Vagner Roberto ELIS \\ Lázaro Valentim ZUQUETTE
}

\begin{abstract}
RESUMO
Foram aplicados ensaios de Sondagem Elétrica Vertical e Sísmica de Refração - na obtenção de informações sobre a transição solo-rocha, profundidade do nível d'água e profundidade e morfologia do topo do substrato rochoso em duas áreas com características geológicas distintas - para avaliar a sua eficiência na obtenção de atributos do meio físico.
\end{abstract}

\section{ABSTRACT}

Vertical Electric Sounding and Refraction Seismic surveys have applied to get information on soil-rock zoning, depth of bedrock and water table in two areas with distinct geological features, to evaluate their relative efficiency in the obtention of physical environment attributes.

\section{INTRODUÇÃO}

Com a crescente preocupação em relação à preservação do meio físico e utilização racional dos recursos naturais, o planejamento e fiscalização da ocupação ganharam grande importância. Os documentos gerados por Mapeamento Geotécnico se apresentam como uma importante ferramenta para orientar esse planejamento, uma vez que retratam as características e as principais variações dos componentes do meio físico.

Dentre essas diversas características, que aqui serão denominadas de atributos, é considerado de extrema importância para o planejamento da ocupação do meio fisico o conhecimento das características da zona de transição solo-rocha, da profundidade do topo rochoso e da profundidade do nível d'água. O conhecimento desses atributos é considerado fundamental para praticamente todos os fatores relacionados à ocupação, como fundações, escavabilidade, disposição de resíduos, estradas, obras enterradas, estabilidade de taludes, erodibilidade, poluição, irrigação e loteamento. Estes atributos anteriormente citados podem em muitos casos ser individualizados através de métodos e técnicas geofísicas.

O objetivo deste trabalho foi obter informações a respeito desses atributos utilizando-se as técnicas de Sondagem Elétrica Vertical e Sísmica de Refração.

\section{METODOLOGIA DE TRABALHO}

Foram realizados ensaios de sondagem elétrica vertical e sísmica de refração em duas áreas com características geológicas dinstintas, nas quais já havia informações geológicas e geotécnicas disponíveis: uma área de rochas sedimentares, em Rio Claro - SP, estudada anteriormente por COTTAS (1983); e uma área de rochas efusivas básicas em Ribeirão Preto SP, estudada por ZUQUETTE (1991). A localização das cidades no Estado de São Paulo é apresentada na figura 1 .

A área de Rio Claro é representada por siltitos e folhelhos da Formação Corumbataí e localiza-se dentro do campus da UNESP, próximo ao Instituto de Biociências (IB). Foram executados 9 ensaios de sondagem elétrica vertical e 4 bases de sísmica de refração. A figura 2 mostra a localização desses ensaios e de perfis que foram construídos individualizando os vários atributos obtidos pela geofísica.

A área de Ribeirão Preto, constituída por basaltos da Formação Serra Geral com a ocorrência em algumas partes de uma cobertura inconsolidada coluvionar, localiza-se no campus da USP, próximo à Faculdade de Filosofia, Ciências e Letras de Ribeirão Preto (FFCLRP). Foram realizados nesta área 7 ensaios de sondagem elétrica vertical e 3 bases de sísmica de refração. A figura 3 mostra a localização desses 


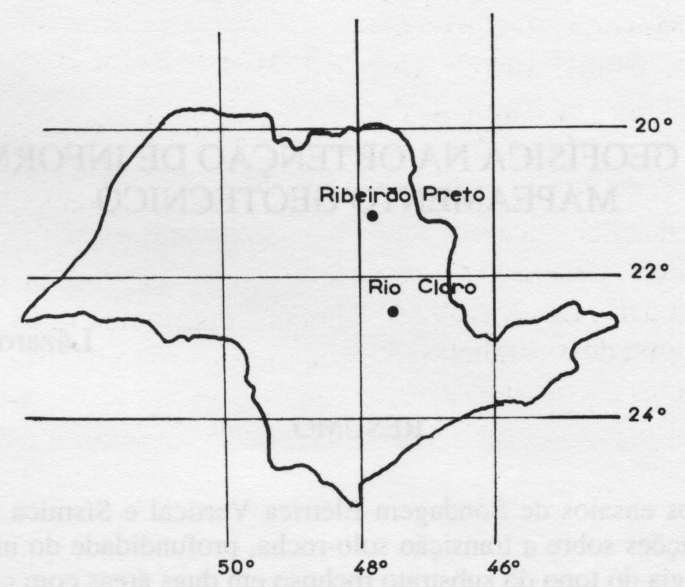

FIGURA 1 - Localização das cidades no Estado de São Paulo.

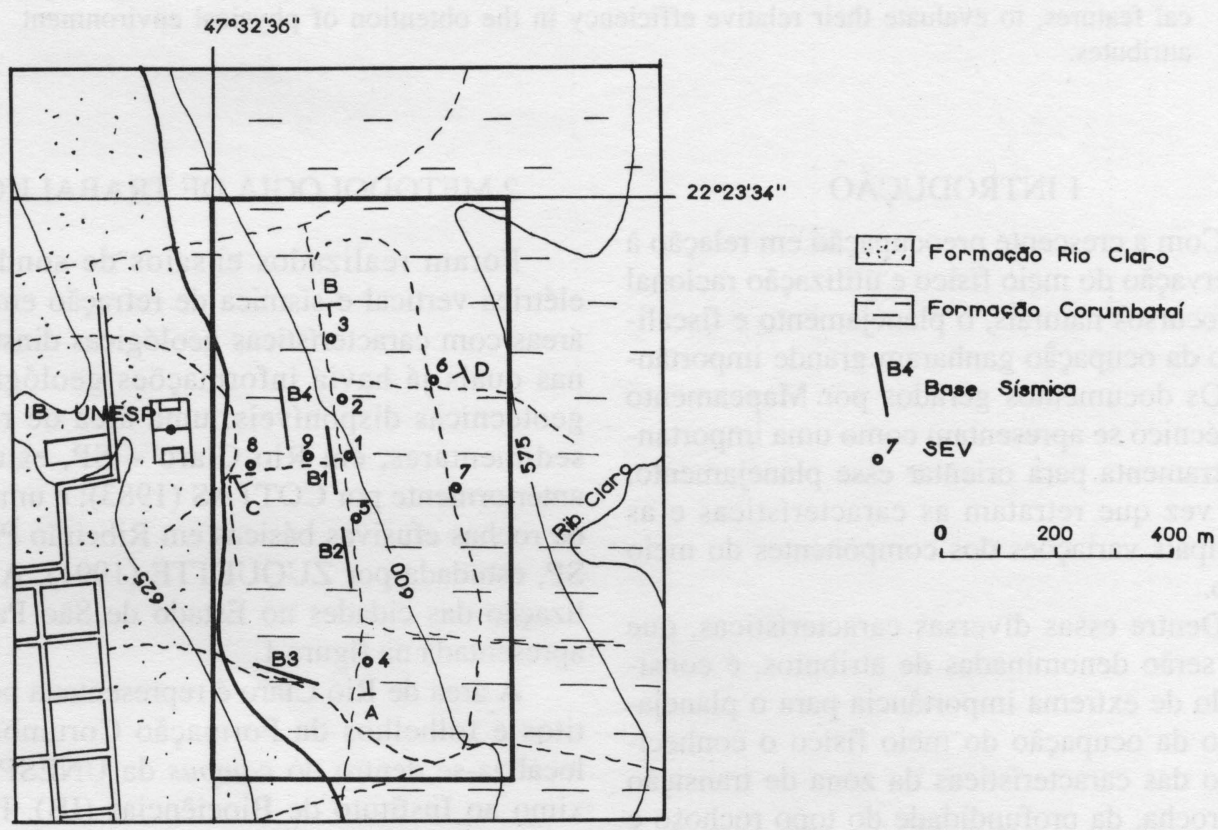

FIGURA 2 - Localização dos ensaios e perfis na área de Rio Claro.

ensaios na área bem como a localização dos perfis que foram construídos.

As SEVs foram executadas nestas áreas com arranjo Schlumberger, sendo as curvas de campo interpretadas em duas etapas: primeiramente, as curvas de campo foram interpretadas pelo método da superposição e ponto auxiliar e este modelo foi posteriormente refinado pelo método de inversão de SEVs usando regressão em cadeia.

Para os ensaios de sísmica de refração, foram utilizadas, como fonte de ondas, cargas de explosivo gelatinoso e um "rifle sísmico" (cartucheira calibre 12 especialmente desenvolvida para ensaios sísmicos). Esses ensaios foram interpretados manualmente pelo Método 
do "ti”(GURVICH, 1972 apud MALAGUTTI FILHO, 1991) e pelo Método Recíproco Generalizado (PALMER, 1980), através do "Software" GREMIX, da Interpex Limited. A partir das velocidades de propagação das ondas longitudinais (P) de cada estrato sísmico, é possível estimar o grau de escarificabilidade através de tabelas construídas pela Caterpillar Tractor Co., de acordo com MEYER \& LESSA (1978). A figura 4 mostra uma dessas tabelas, a qual foi utilizada para estimar o grau de escarificabilidade dos materiais investigados neste trabalho.

\section{DISCUSSÃO DOS RESULTADOS}

\section{1 Área de Rio Claro}

Através dos ensaios realizados, foi possível caracterizar a zona de transição solo-rocha, definir a profundidade do topo rochoso e a profundidade do nível d'água. Os perfis interpretados são mostrados na figura 5 , onde se pode notar a distribuição dos vários estratos da transição solo-rocha (solo supercial, saprolito e topo da rocha sã) e a profundidade do nível d'água.

De uma forma geral, os ensaios geofísicos

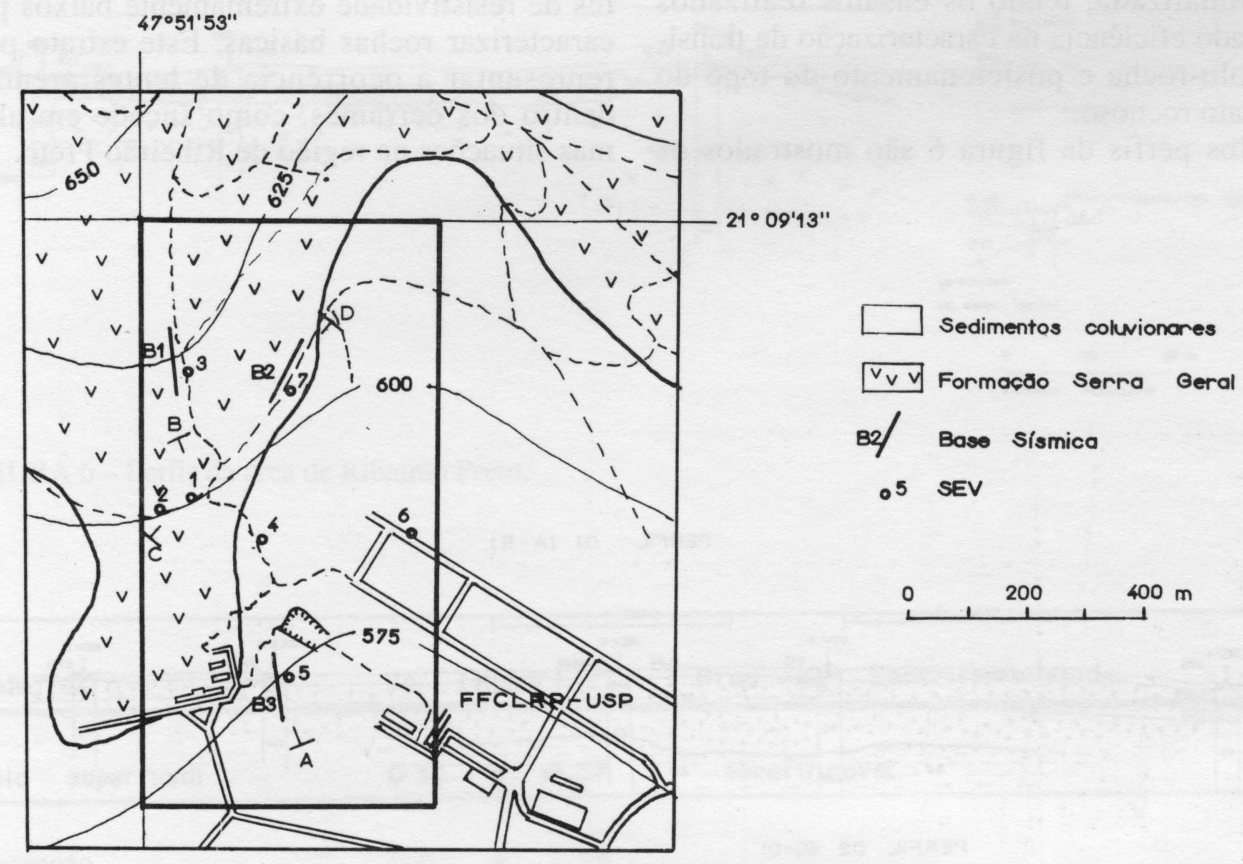

FIGURA 3 - Localização dos ensaios e perfis na área de Ribeirão Preto.

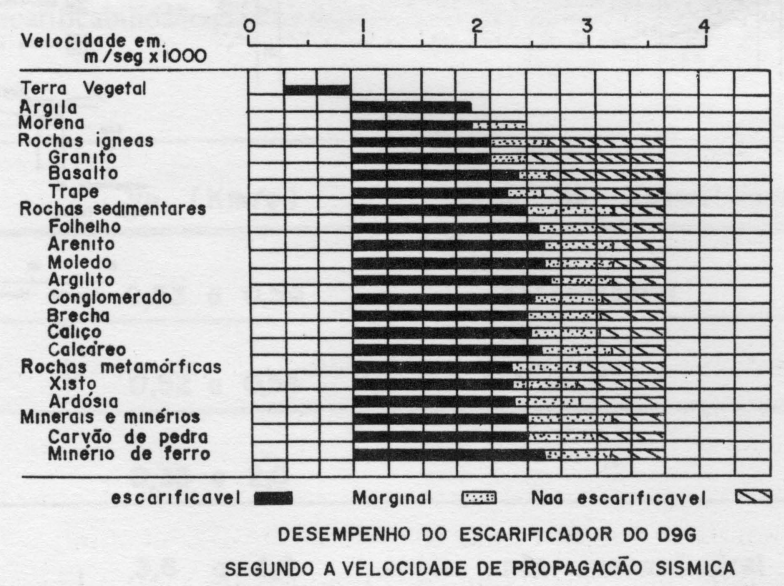

FIGURA 4 - Escarificabilidade como função de Vp para diferentes tipos de materiais (MEYER \& LESSA, 1978). 
apresentaram bons resultados na obtenção dos atributos investigados. Os resultados obtidos para profundidade do saprolito e profundidade do nível d'água se aproximam bastante dos resultados obtidos por COTTAS (1983).

$\mathrm{O}$ grau de escacificabilidade dos diversos materiais da área foi estimado e é apresentado na tabela 1 .

\section{2 Área de Ribeirão Preto}

$\mathrm{Na}$ área de Ribeirão Preto ocorre, em algumas partes, uma cobertura de material inconsolidado coluvionar, que pode perfeitamente ser individualizada, tendo os ensaios realizados mostrado eficiência na caracterização da transição solo-rocha e posicionamento do topo do substrato rochoso.

Nos perfis da figura 6 são mostrados os vários estratos obtidos pela geofísica: solo superficial, cobertura inconsolidada coluvionar (quando ocorre), saprolito e topo do substrato rochoso. Não foi possível a definição da profundidade do nível d'água, devido provavelmente ao caráter argiloso dos produtos de alteração do basalto, que mesmo com um baixo grau de saturação tendem a apresentar valores de resistividade muito baixos, não permitindo assim que haja contraste elétrico entre a zona insaturada e a zona saturada.

Além desses vários estratos, ocorre em algumas SEVs, abaixo da rocha sã definida pela sísmica, um estrato geoelétrico com valores de resistividade extremamente baixos para caracterizar rochas básicas. Este estrato pode representar a ocorrência de lentes arenosas dentro dos derrames, como sucede em algumas situações na região de Ribeirão Preto.

PERFIL OI (A-B)
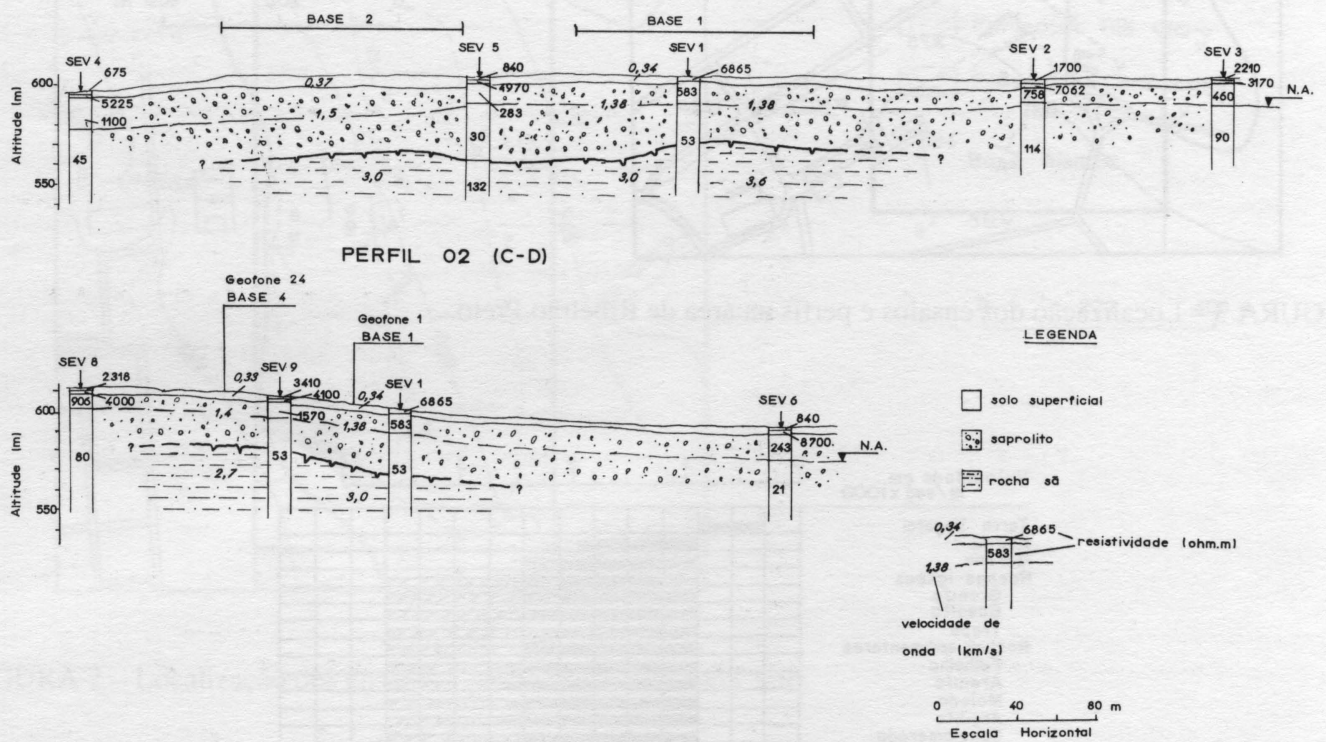

FIGURA 5 - Perfis da área de Rio Claro 


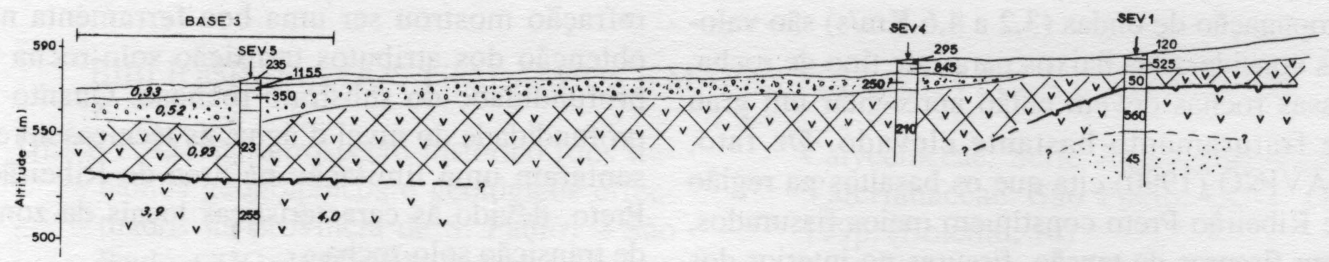

LEGENDA

PERFIL $02 \quad(C-D)$

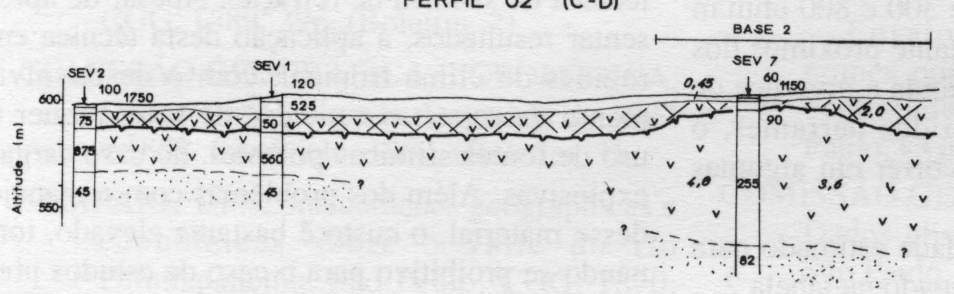

FIGURA 6 - Perfis da área de Ribeirão Preto. $\square$ •olo superficiol

图 colúvio

国 soprolito

[Vy rocho so

圆 lente orenoso (?)

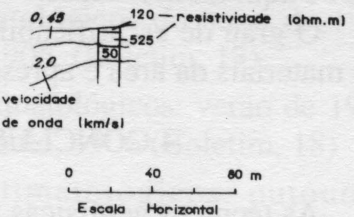

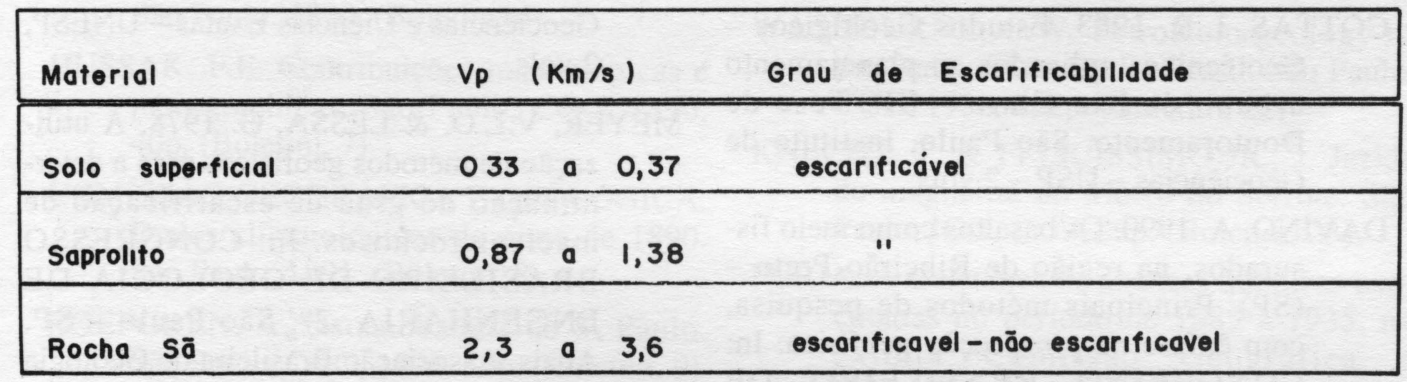

TABELA 1 - Grau de escarificabilidade para os materiais da área de Rio Claro.

\begin{tabular}{|lll|}
\hline Materıal & Vp $(\mathrm{Km} / \mathrm{s})$ & Grau de Escarificabilidade \\
\hline \hline Solo superficıal & 0,33 a 0,54 & escarificável \\
\hline Colúvio & 0,52 a 0,54 & " \\
\hline Saprolito & 0,33 a 2,0 & " \\
\hline Substrato rochoso & 3,6 a 4,4 & nāo escarificaivel \\
\hline
\end{tabular}

TABELA 2 - Grau de escarificabilidade para os materiais da área de Ribeirão Preto. 
Um fato que merece atenção é que tanto os valores de resistividade obtidos para os basaltos (225 a 1160 ohm.m) como as velocidades de propagação de ondas $(3,2$ a 4,6 Km/s) são valores considerados baixos para este tipo de rocha. Essas rochas devem então apresentar um grau de fraturamento bastante elevado. De fato, DAVINO (1990) cita que os basaltos na região de Ribeirão Preto constituem meios fissurados, com fissuras de tensão, fissuras no interior dos derrames e juntas-falha horizontais. $\mathrm{O}$ autor realizou ensaios de SEVs na região e obteve valores de resistividadc entre 300 e 800 ohm.m para os basaltos, valores bastante próximos dos obtidos neste trabalho. Cita ainda a presença de sedimentos arenosos dentro dos derrames, o que, como já citado, deve ocorrer em algumas SEVs aqui mencionadas.

O grau de escarificabilidade estimado para os materiais da área é apresentado na tabela 2.

\section{CONCLUSÕES}

As técnicas geofísicas utilizadas apresentaram um comportamento bastante satisfatório na determinação das variações espaciais de alguns atributos importantes para elaboração de mapeamento geotécnico. A aplicação conjunta de sondagem elétrica vertical e sísmica de refração mostrou ser uma boa ferramenta na obtenção dos atributos transição solo-rocha e profundidade do substrato rochoso. Quanto à profundidade do nível d'água, as técnicas apresentaram uma limitação na área de Ribeirão Preto, devido às características locais da zona de transição solo-rocha.

Outra limitação da metodologia utilizada é de caráter econômico e se refere à aplicação da técnica de sísmica de refração. Apesar de apresentar resultados, a aplicação desta técnica em regiões de clima tropical, com o desenvolvimento de espessas camadas de solo, requer o uso de fontes sísmicas potentes, no caso cargas explosivas. Além dos problemas com o manejo desse material, o custo é bastante elevado, tornando-se proibitivo para o caso de estudos preliminares, isto é, mapeamentos geotécnicos de áreas de grande extensão. A metodologia pode se tornar interessante no caso de trabalhos de detalhe para implantação de obras de engenharia, onde a relação custo/benefício alcance valores mais viáveis.

\section{REFERÊNCIAS BIBLIOGRÁFICAS}

COTTAS, L.R. 1983. Estudos Geológicos Geotécnicos aplicados ao planejamento urbano de Rio Claro - SP. Tese de Doutoramento, São Paulo, Instituto de Geociências - USP - 2 vols.

DAVINO, A. 1990. Os basaltos como meio fissurados, na região de Ribeirão Preto (SP). Principais métodos de pesquisa, com ênfase na prospecção geofísica. In: CONGRESSO BRASILEIRO DE GEOLOGIA, 36은 Natal - RN. Anais. Sociedade Brasileira de Geologia, v.5, p. $531-852$.

MALAGUTTI FILHO, W. 1991. Utilização de técnicas geofísicas na caracterização de solos e rochas com aplicações na geologia de planejamento urbano. Tese de Doutorado, Rio Claro, Instituto de
Geociências e Ciências Exatas - UNESP, 2 vols.

MEYER, V.L.O. \& LESSA, G. 1978. A utilização de métodos geofísicos para a determinação do grau de escarificação de maciços rochosos. In: CONGRESSO BRASILEIRO DE GEOLOGIA DE ENGENHARIA, 2으, São Paulo - SP. Anais. Associação Brasileira de Geologia de Engenharia, v. 2, págs. 31-46.

PALMER, D.F. 1980. The Generalized Reciprocal Method of seismic refraction interpretation. Soc. Exploration Geophysics.

ZUQUETTE, L.V. 1991: Mapeamento Geotécnico. Uma nova Abordagem. Relatório Científico FAPESP, 2 vols.

Vagner Roberto Elis - Departamento de Geologia Geral/UFMT - Avenida Fernando Correa da Costa s/nº, 78090-100 - Cuiabá - MT. Lázaro Valentim Zuquette - Faculdade de Filosofia, Ciências e Letras de Ribeirão Preto/USP - Avenida Bandeirantes, 3.900 - 14049-000 Ribeirão Preto - SP - Brasil. 